\title{
Expression of Concern: Modulation of gut microbiota by antibiotics improves insulin signalling in high-fat fed mice
}

\author{
B. M. Carvalho ${ }^{1}$ D. Guadagnini ${ }^{1}$ - D. M. L. Tsukumo ${ }^{1}$ - A. A. Schenka ${ }^{1}$. \\ P. Latuf-Filho ${ }^{1}$ - J. Vassallo ${ }^{1}$ - J. C. Dias ${ }^{2}$ - L. T. Kubota ${ }^{2}$ - J. B. C. Carvalheira ${ }^{1}$. \\ M. J. A. Saad ${ }^{1}$
}

(C) Springer-Verlag Berlin Heidelberg 2017

\section{Expression of Concern to: Diabetologia}

DOI 10.1007/s00125-012-2648-4

On the basis of the recommendation of the EASD's Scientific Integrity Panel, the Editor-in-Chief is issuing this expression of concern to alert readers to questions about the reliability of some of the data in the article cited above.

In particular it appears that the immunoblots for total IKK $\beta$ in Fig. $4 \mathrm{~g}$ and $\mathrm{k}$ of this paper may have been duplicated.
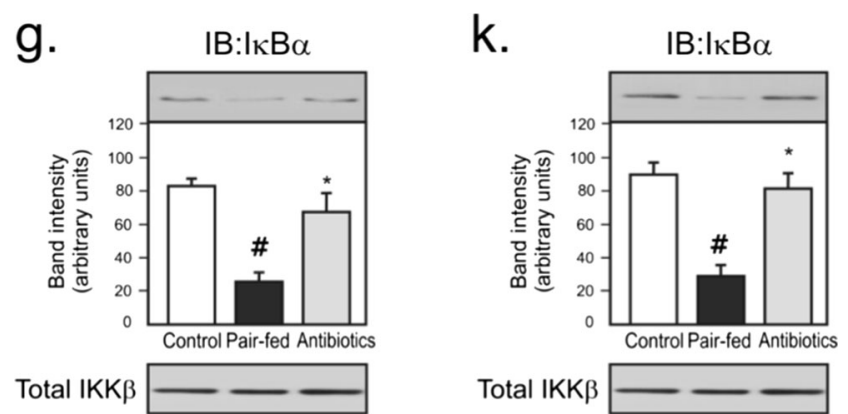

The online version of the original article can be found at http://dx.doi.org/ $10.1007 / \mathrm{s} 00125-012-2648-4$

\section{J. A. Saad}

msaad@fcm.unicamp.br

1 Internal Medicine Department-Faculty of Medical Sciences,

State University of Campinas,

Rua Tessália Vieira de Camargo,

126, Cidade Universitária Zeferino Vaz,

Campinas, São Paulo 13083-887, Brazil

2 Chemistry Institute, State University of Campinas,

Campinas, São Paulo, Brazil
In line with guidelines issued by the Committee on Publication Ethics (COPE), the journal has informed the corresponding author, Mario Saad, of this concern. The author's response was considered unsatisfactory and the low resolution of the images provided to us prevented further analysis to conclusively confirm or refute this possible duplication. The University of Campinas (São Paulo, Brazil) was asked, in March 2016, to undertake an institutional investigation. As no results from this investigation have been forthcoming this expression of concern is being issued to alert readers to exercise caution when interpreting the content and conclusions of this article. This expression of concern will remain in place until such a time as further evidence is available. 